\title{
Stimulatory Effects of Sublethal Doses of Carbendazim on the Virulence and Sclerotial Production of Botrytis cinerea
}

\author{
Menglong Cong, Bao Zhang, Kunyu Zhang, Guoqing Li, and Fuxing Zhu ${ }^{\dagger}$ \\ College of Plant Science and Technology, Huazhong Agricultural University, Wuhan, 430070, China
}

\begin{abstract}
Stimulatory effects of low doses of fungicides on the virulence of phytopathogens have profound implications for applications of fungicides. The present study demonstrated that carbendazim sprayed at 0.001 to $0.03 \mu \mathrm{g} / \mathrm{ml}$ had stimulatory effects on the virulence of mycelia of Botrytis cinerea, and the maximum percent stimulations were 15.5 and $21.4 \%$ for isolates HB459 and HB536, respectively. Potato dextrose agar (PDA) amended with carbendazim at 0.01, 0.02, and $0.05 \mu \mathrm{g} / \mathrm{ml}$ inhibited mycelial growth of isolate HB536 by $0.8,10.0$, and $30.6 \%$, respectively. However, after the inhibited mycelia were inoculated on cucumber leaves, virulence increased by 10.1, 12.9, and $10.8 \%$, respectively. With respect to sclerotial production, carbenda-

number and weight of both isolates compared with nontreated controls. Conidia germination percentages slightly yet statistically significantly $(P<0.05)$ increased after being inoculated on PDA amended with carbendazim at 0.001 and $0.005 \mu \mathrm{g} / \mathrm{ml}$. Carbendazim at $0.001 \sim 0.02 \mu \mathrm{g} / \mathrm{ml}$, either sprayed on cucumber leaves or cosuspended with conidia, exerted significantly $(P<0.05)$ stimulatory effects on the virulence of $B$. cinerea conidia. Mechanism studies showed that sublethal doses of carbendazim did not increase the expression levels of pathogenicity-related pectin methylesterase gene Bcpme1, endopolygalacturonase gene $B c p g 2$, cutinase gene $C u t A$, xylanase gene Xyn11A, or NADPH oxidase gene BcnoxA.
\end{abstract} zim at 0.005 and $0.02 \mu \mathrm{g} / \mathrm{ml}$ in PDA significantly $(P<0.05)$ increased, while at $0.1 \mu \mathrm{g} / \mathrm{ml}$ significantly $(P<0.05)$ reduced the sclerotial

Keywords: fungi, fruit, small fruits, disease management, chemical

Hormesis is a dose-response model depicting the phenomenon of low-dose stimulation and high-dose inhibition. The hormetic doseresponse model is biphasic, usually represented by either an inverted U shaped or a J-shaped curve (Calabrese 2015a). The concept of hormesis has received considerable interest in the toxicological and pharmacological fields, and publications and citations of hormesis have increased dramatically in the past two decades (Calabrese 2013, 2018a, 2018b). As of 2011, more than 9,000 hormetic doseresponse cases had been recorded in a relational retrieval hormesis database (Calabrese and Blain 2011). The quantitative features and mechanisms of hormesis, including preconditioning and postconditioning hormesis, have been extensively studied and systematically reviewed (Calabrese 2013, 2015a, 2015b, 2016a, 2016b, 2018a, 2018b; Calabrese and Agathokleous 2019).

Hormetic effects of fungicides on plant pathogens have important implications for chemical control of plant diseases. Sublethal doses of a fungicide may increase mycelial growth rate, virulence, and fungicide tolerance of plant pathogens (Garzón and Flores 2013; Lu et al. 2018a, 2018b). Numerous cases of fungicide hormesis have been reported, including stimulatory effects of mefenoxam, propamocarb, and cyazofamid on mycelial growth and virulence of Pythium aphanidermatum (Flores and Garzón 2013; Garzón et al. 2011), metalaxyl on mycelial growth of Phytophthora infestans (Zhang et al. 1997), thiabendazole on spore germination of Penicillium expansum (Baraldi et al. 2003), thiophanate-methyl on mycelial growth of Sclerotinia homoeocarpa (Pradhan et al. 2019), and carbendazim (Di et al. 2015, 2016b), dimethachlone (Zhou et al. 2014), flusilazole (Lu et al. 2018a, 2018b), prochloraz (Zhang et al. 2019), and trifloxystrobin (Di et al. 2016a) on pathogenicity of S. sclerotiorum. Mycotoxin

${ }^{\dagger}$ Corresponding author: F. Zhu; zhufuxing@mail.hzau.edu.cn

Funding: This study was supported by the National Natural Science Foundation of China, grant no. 31371964.

The author(s) declare no conflict of interest.

Accepted for publication 8 April 2019.

C 2019 The American Phytopathological Society production could be stimulated by sublethal doses of fungicides. For example, the triazole fungicide prothioconazole at sublethal concentrations increases production of the mycotoxin deoxynivalenol in Fusarium graminearum (Audenaert et al. 2010).

The necrotrophic fungal pathogen Botrytis cinerea can infect more than 1,400 plant species, including many agriculturally important crops, fruits, and vegetables (Van Kan et al. 2017). B. cinerea is difficult to control, and thus integrated measures including resistant cultivars, good garden stewardship, biological, and chemical measures are usually recommended. Among the variety of control measures, fungicides have been the mainstay treatment (Mbengue et al. 2016; Nakajima and Akutsu 2014; Williamson et al. 2007). Extensive and repeated applications of fungicide will inevitably lead to fungicide resistance. Resistance to carbendazim in $B$. cinerea has been widely reported worldwide (Fan et al. 2017; Konstantinou et al. 2015; Rupp et al. 2017; Saito et al. 2016). In recent papers, we have reported stimulatory effects of carbendazim on the virulence of carbendazim-resistant B. cinerea (Cong et al. 2018, 2019). However, fungicide stimulatory effects on wild-type sensitive $B$. cinerea remain to be studied. Our previous studies showed that virulence stimulation by carbendazim is not caused by oxalic acid, which has been shown to play an important role in the pathogenicity of $B$. cinerea and S. sclerotiorum (Cong et al. 2018; Di et al. 2015; Nakajima and Akutsu 2014). Therefore, to explore the hormetic mechanisms of carbendazim, we measured the expression levels of other virulence-associated factor genes, including the pectin methylesterase gene Bcpme1, the endopolygalacturonase gene Bcpg2 (Zhang et al. 2014), the cutinase gene CutA (Van der Vlugt-Bergmans et al. 1997), the xylanase gene Xyn11A (Brito et al. 2006), and the NADPH oxidase gene BcnoxA (Segmüller et al. 2008). The objectives of the present study were to (i) determine the hormetic effects of carbendazim on the virulence of sensitive $B$. cinerea, (ii) assay the stimulatory effects of carbendazim on sclerotial production and conidial germination of $B$. cinerea, and (iii) assess effects of sublethal doses of carbendazim on the expression levels of several virulenceassociated genes.

\section{Materials and Methods}

Isolates of B. cinerea. Isolates HB459 and HB536 were collected from diseased tomatoes in Hubei Province, China. Mycelial colonies were maintained on potato dextrose agar (PDA) slants at $4{ }^{\circ} \mathrm{C}$. 
Fungicide sensitivity assays using 5 serially diluted concentrations of carbendazim showed that the effective concentrations of carbendazim inhibiting mycelial growth by $50 \%\left(\mathrm{EC}_{50}\right)$ for isolates $\mathrm{HB} 459$ and HB536 were 0.05 and $0.07 \mu \mathrm{g} / \mathrm{ml}$, respectively.

Fungicide. Technical grade carbendazim $(98.1 \%$ active ingredient) was provided by Tian Jin Jin Bei Fine Chemical Co. Ltd. and dissolved in $0.1 \mathrm{~mol} /$ liter of hydrochloric acid $(\mathrm{HCl})$ to produce a stock solution at $1,000 \mu \mathrm{g} / \mathrm{ml}$. The stock solution was stored at $4^{\circ} \mathrm{C}$ and diluted within the next 2 weeks for subsequent experiments.

Stimulatory effects of spraying sublethal doses of carbendazim on the virulence of $B$. cinerea on cucumber plants. Inoculation and spraying procedures were described by Cong et al. (2018). The stock solution of carbendazim was serially diluted with sterilized water containing $0.1 \%(\mathrm{vol} / \mathrm{vol})$ Triton $\mathrm{X}-100$ to concentrations of

Table 1. Nucleotide sequences of the primers used in the study

\begin{tabular}{lll}
\hline Target gene & Forward primer sequence $\left(\mathbf{5}^{\prime} \mathbf{-} \mathbf{3}^{\prime}\right)$ & Reverse primer sequence $\left(\mathbf{5}^{\prime} \mathbf{-} \mathbf{3}^{\prime}\right)$ \\
\hline$\beta$-tubulin & GCAAGACGCGTCGACTTTAC & CCCTGAGCAGATTGTCAGCA \\
Bcpg2 & GGAACTGCCACTTTTGGTTAC & TCCATCCCACCATCTTGCTC \\
CutA & AGGCTGGTTCGAGAATGGTT & CCCTGCAAAACTAGCATCTCC \\
Xyn11A & TGTTGGTTCCGAGCGCTCC & GGGAGGTAGTCCAACCATAGACGG \\
BcnoxA & CACGGAACAAATCCTCCCGA & CAGGTTGTCCTGCTGCTTCT \\
Bcpme1 & TGGGACGTCCATGGAGAAAC & TGATGCCGGAACTGAAGGTT \\
\hline
\end{tabular}
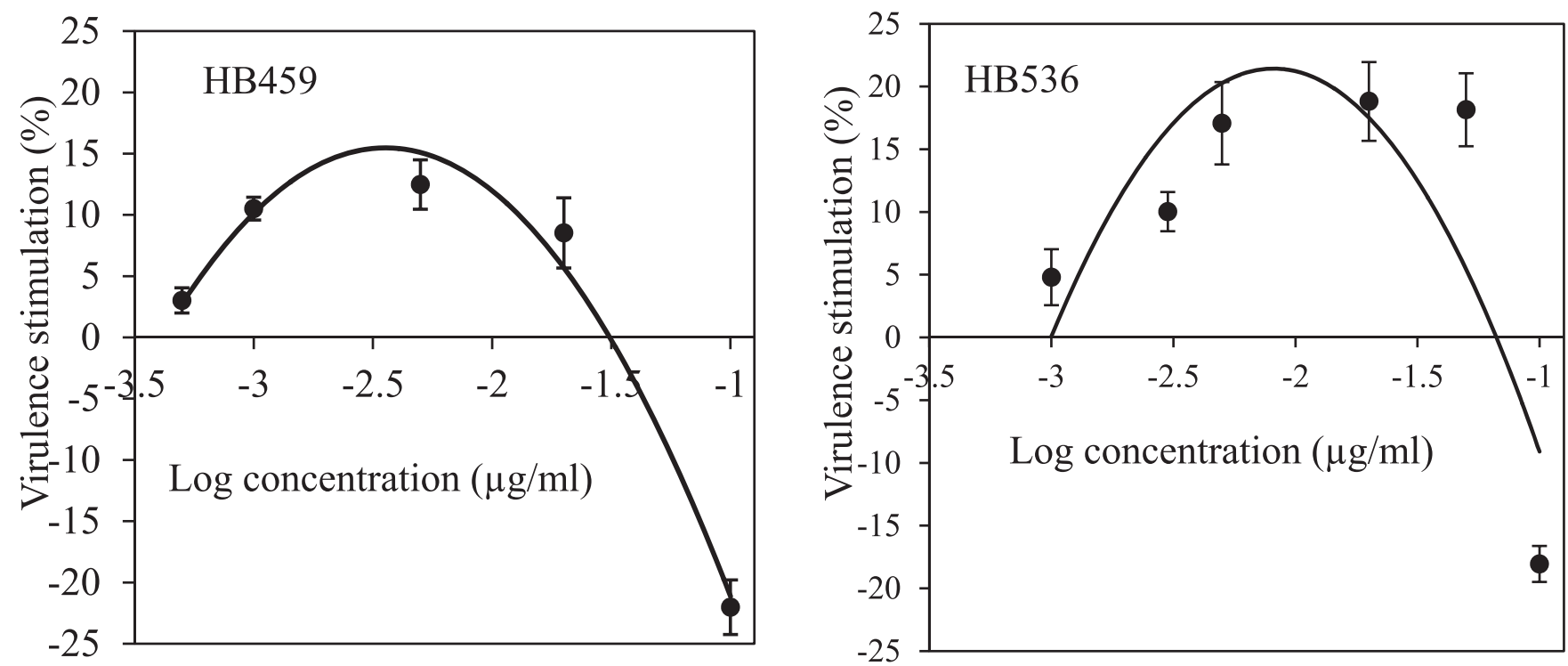

Fig. 1. Stimulatory effects of spraying sublethal doses of carbendazim on the virulence of Botrytis cinerea isolates HB459 and HB536 on potted cucumber plants. Data are the mean value of four repetitions, and error bars denote standard error of the mean.
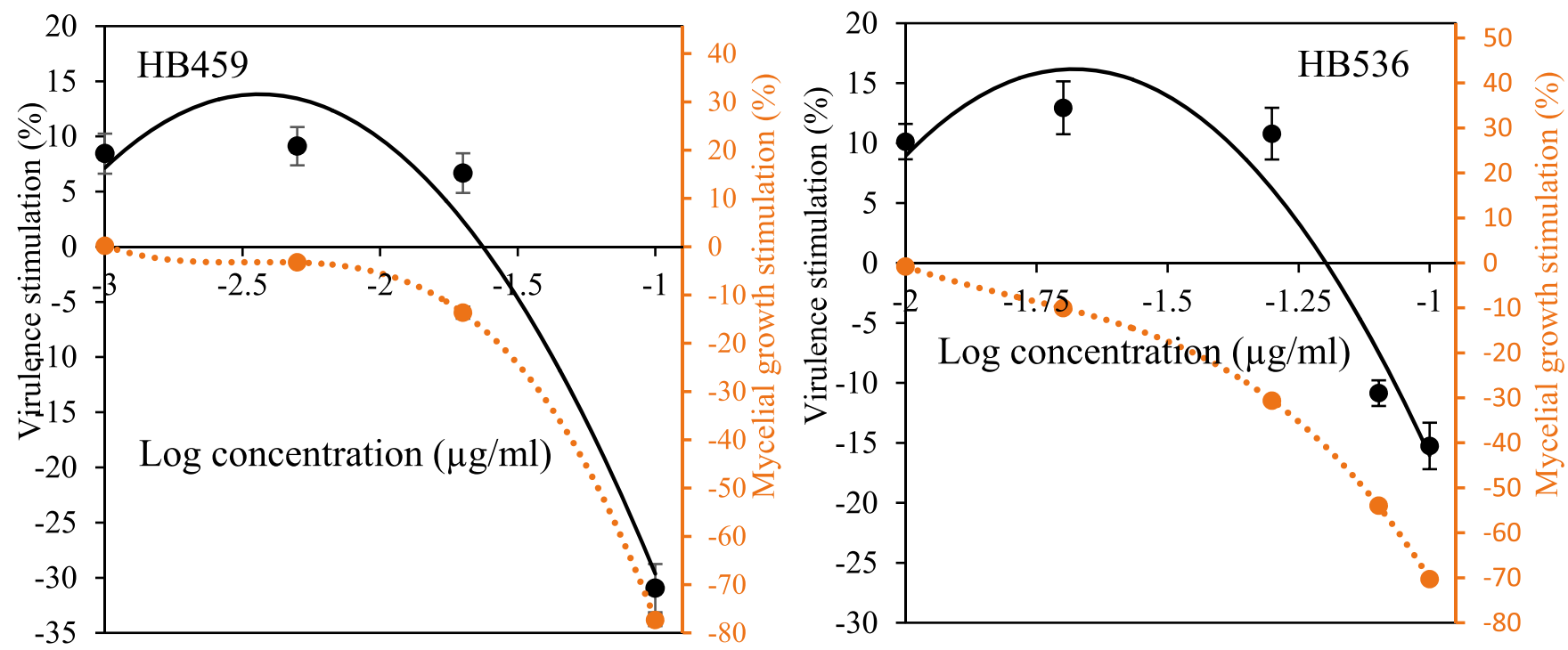

Fig. 2. Stimulatory effects of growing (preconditioning) on carbendazim-amended PDA on the virulence of Botrytis cinerea isolates HB459 and HB536 on detached leaves of cucumber plants. Data are the mean value of five repetitions, and error bars denote standard error of the mean. Solid lines denote virulence stimulation, and dotted lines denote mycelial growth stimulation. 
$0.0005,0.001,0.005,0.02$, and $0.1 \mu \mathrm{g} / \mathrm{ml}$ for isolate HB459; and $0.001,0.003,0.005,0.02,0.05$, and $0.1 \mu \mathrm{g} / \mathrm{ml}$ for isolate HB536. The concentrations of carbendazim were set according to the results of preliminary experiments to give parabolic stimulation curves. Carbendazim dilutions were sprayed until runoff by a hand-held sprayer ( $800 \mathrm{ml}$ in volume, Xinmeir Co. Ltd.) on potted 5-week-old cucumber leaves (cultivar 'Jinyou 1'). Two cucumber plants sprayed with water containing $0.1 \%$ Triton X-100 were used as the nontreated control. After being air-dried for $1 \mathrm{~h}$, two leaves of each cucumber plant were inoculated on the adaxial surface with inverted 5-mm-diameter mycelial plugs cut from 3-day-old colonies. The inoculated cucumber plants were incubated at $25^{\circ} \mathrm{C}$ for $72 \mathrm{~h}$ with relative humidity maintained at approximately $90 \%$. The diameter of each lesion was measured twice at right angles. The experiment was conducted independently four times, and for each time the experiment was arranged as a completely randomized design (CRD) with two replicate cucumber plants for each treatment.

Stimulatory effects of preconditioned mycelia grown on carbendazim-amended PDA on the virulence of $B$. cinerea. Mycelial colonies were grown at $23^{\circ} \mathrm{C}$ on PDA amended with carbendazim at $0.001,0.005,0.02$, and $0.1 \mu \mathrm{g} / \mathrm{ml}$ for isolate HB459; and at $0.01,0.02,0.05,0.08$, and $0.1 \mu \mathrm{g} / \mathrm{ml}$ for isolate HB536 for $72 \mathrm{~h}$ as the preconditioning treatment. Leaves of similar size $(8$ to $11 \mathrm{~cm}$ in diameter) and position were detached from 5-week-old cucumber plants and placed in 15-cm-diameter petri dishes lined with watersoaked filter paper to maintain high humidity. The detached leaves were inoculated with mycelial plugs cut from fresh margins of 3day-old preconditioned mycelial colonies. The lowest concentrations of carbendazim were set at 0.001 and $0.01 \mu \mathrm{g} / \mathrm{ml}$ for isolates HB459 and HB536, respectively, to give almost negligible mycelial growth inhibitions. Leaves inoculated with mycelial plugs cut from culture colonies growing on PDA amended with $\mathrm{HCl}$ at a final concentration of $0.001 \mathrm{~mol} / \mathrm{liter}$, which was the same as in carbendazim treatments, were used as the nontreated control. After the inoculated leaves were incubated at $25^{\circ} \mathrm{C}$ for $72 \mathrm{~h}$ with relative humidity maintained at approximately $90 \%$, the diameter of each lesion was measured twice at right angles. The experiment was arranged as a CRD with three replicate leaves for each treatment and conducted independently five times.

Effects of carbendazim on sclerotial production of $B$. cinerea. PDA was supplemented with carbendazim at final concentrations of $0.0005,0.001,0.005,0.02$, and $0.1 \mu \mathrm{g} / \mathrm{ml}$. PDA amended with 0.002 $\mathrm{mol} / \mathrm{liter} \mathrm{HCl}$ was used as the nontreated control. Mycelial plugs, $5 \mathrm{~mm}$ in diameter, cut from actively growing margins of culture

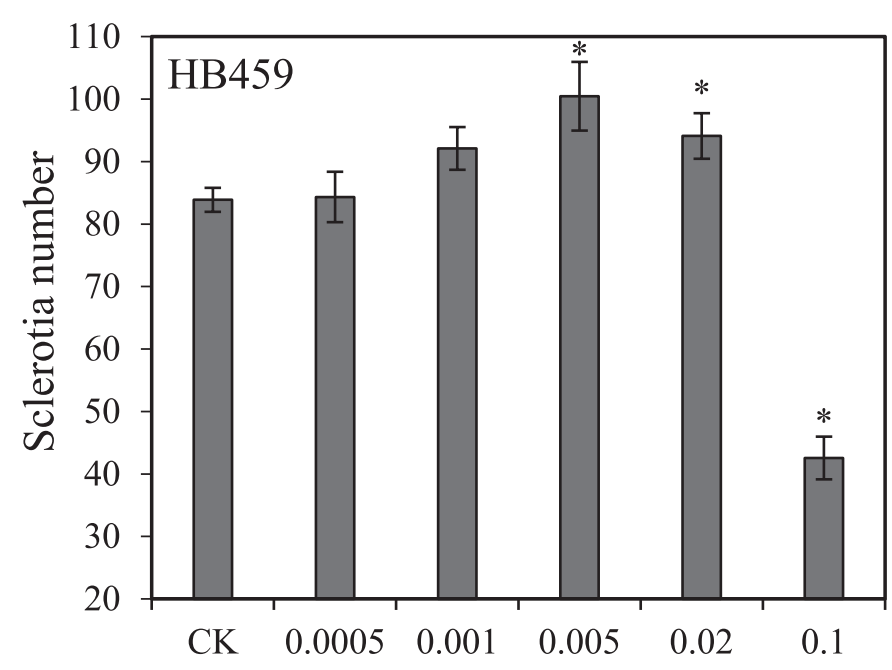

Concentration of carbendazim $(\mu \mathrm{g} / \mathrm{ml})$

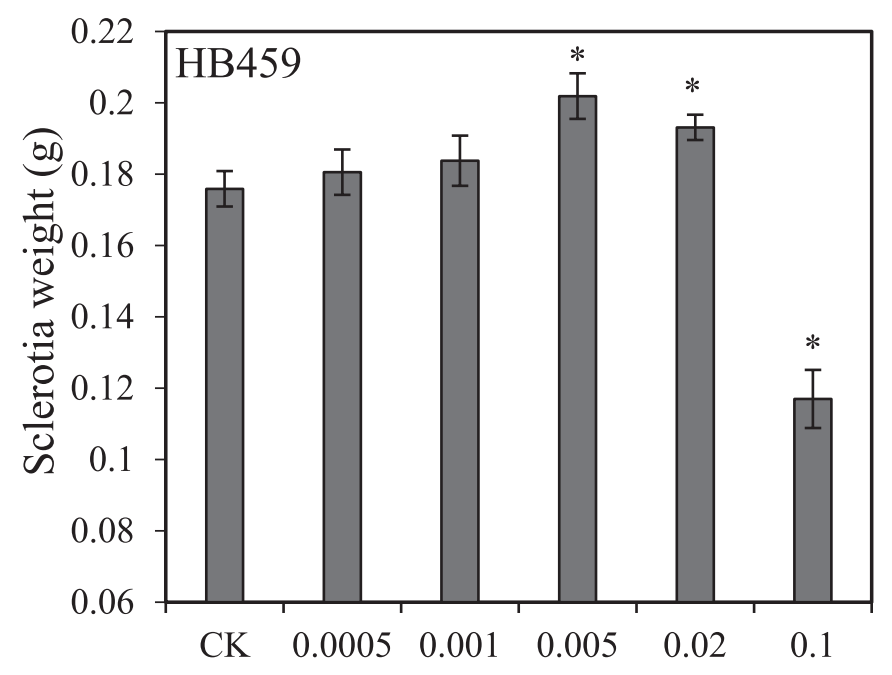

Concentration of carbendazim $(\mu \mathrm{g} / \mathrm{ml})$
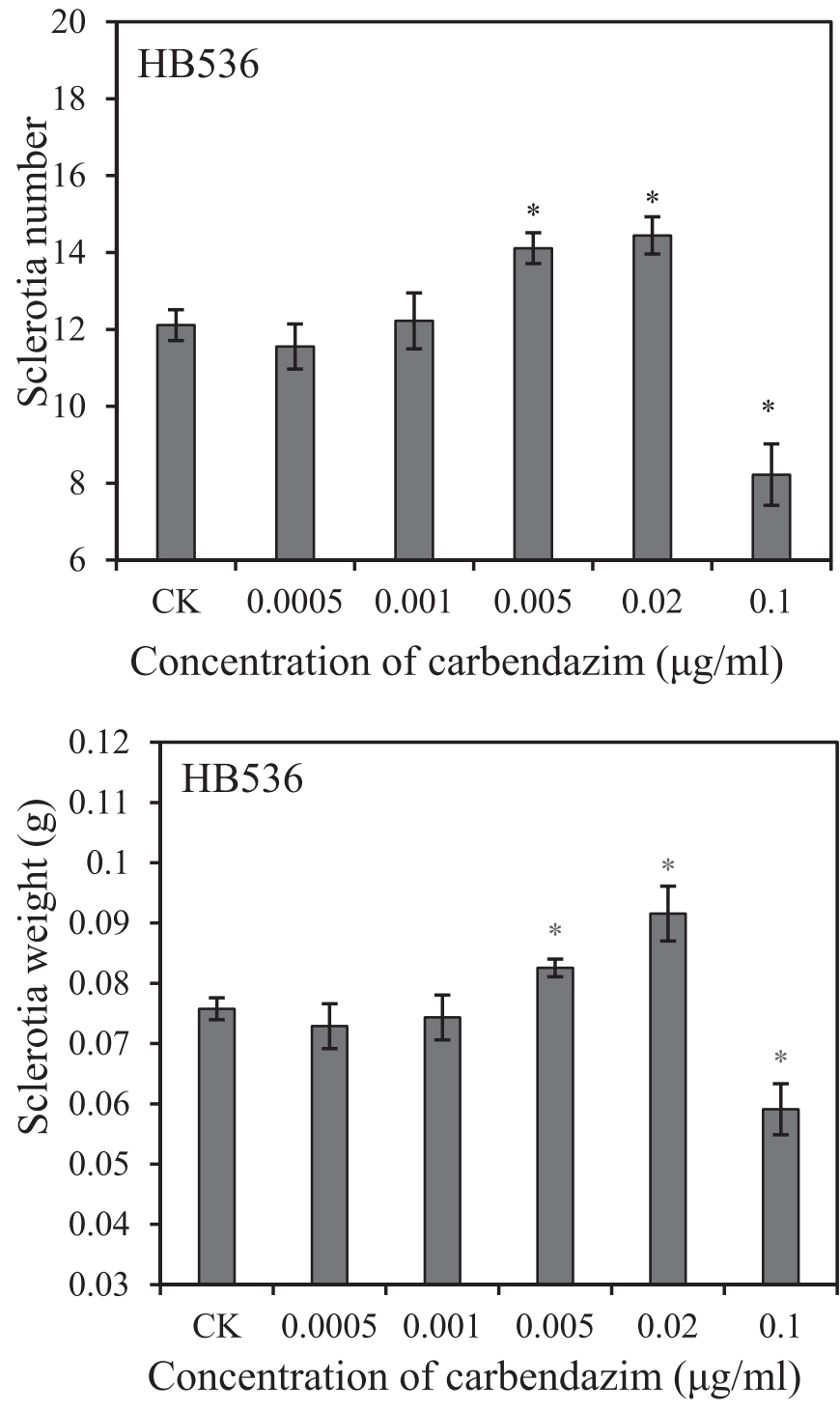

Fig. 3. Effects of sublethal doses of carbendazim on the number and weight of Botrytis cinerea sclerotia produced per PDA plate. Data are the mean value of three repetition experiments and error bars denote standard error of the mean. Asterisks denote significant difference at $\alpha=0.05$ compared with the nontreated control according to the least significant difference (LSD) test. CK denotes nontreated control. 
colonies of isolates HB459 and HB536, were inoculated on the center of each PDA plate amended with carbendazim or $\mathrm{HCl}$. Three replicate PDA plates for each isolate were incubated at $23^{\circ} \mathrm{C}$ in the dark for 30 days. Sclerotia produced on each PDA plate were counted and weighed together after being dried at $50^{\circ} \mathrm{C}$ for $48 \mathrm{~h}$. The experiment was performed independently three times.

Effects of sublethal doses of carbendazim on conidial germination of B. cinerea. Fresh mycelial plugs of isolates HB459 and HB536 were inoculated on PDA in 9-cm-diameter petri dishes and incubated at $23^{\circ} \mathrm{C}$ in the dark for 14 days. An aliquot of $2 \mathrm{ml}$ sterile water was pipetted onto each dish and conidia were suspended by gentle scraping with a pipette tip. Conidial suspensions were filtered through a 200-mesh stainless steel wire screen and conidia were counted with a hemocytometer under a light microscope. An aliquot of $20 \mu \mathrm{l}$ of conidia suspension at approximately $1 \times 10^{6} / \mathrm{ml}$ was pipetted and plated onto each PDA plate amended with carbendazim

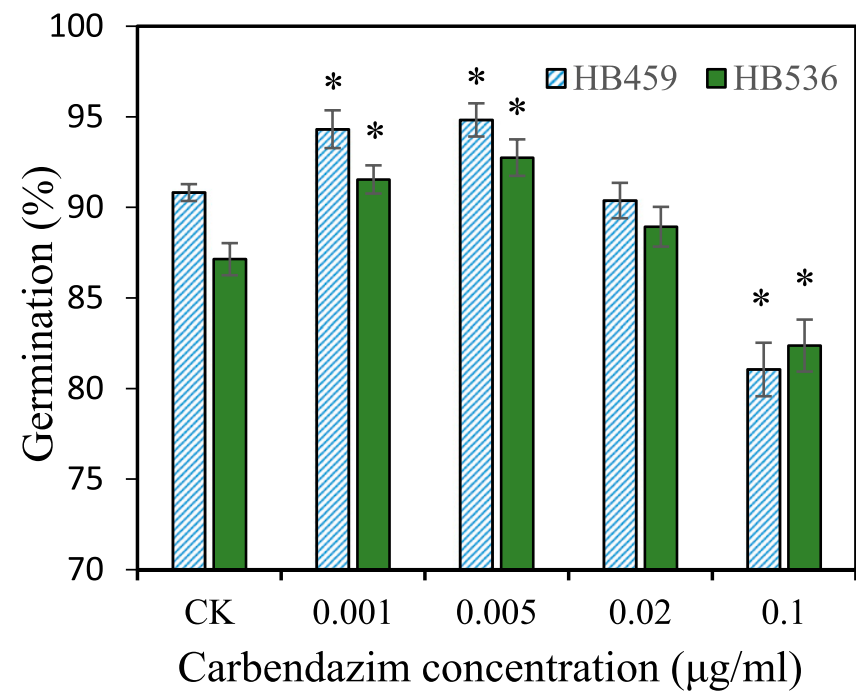

Fig. 4. Effects of sublethal doses of carbendazim on conidial germination of Botrytis cinerea isolates HB459 and HB536. Data are the mean value of three repetition experiments and error bars denote standard error of the mean. Asterisks denote significant difference at an $\alpha$-level of 0.05 when compared with the nontreated control according to the least significant difference (LSD) test. CK denotes nontreated control. at $0.001,0.005,0.02$, and $0.1 \mu \mathrm{g} / \mathrm{ml}$. PDA amended with $0.002 \mathrm{~mol} /$ liter $\mathrm{HCl}$ was used as the nontreated control. After being incubated at $23^{\circ} \mathrm{C}$ in the dark for $8 \mathrm{~h}$, germination of conidia was observed with a light microscope. For each plate, at least 300 conidia were visually assessed microscopically ( $\times 100$ magnification), and a conidium was considered to have germinated if the germ tube was at least as long as the length of the conidium. The experiment was conducted in triplicate and performed independently three times.

Stimulatory effects of spraying sublethal doses of carbendazim on the virulence of conidia of $\boldsymbol{B}$. cinerea. Conidia were collected from 2-week-old colonies as described above. Carbendazim dilutions were sprayed on the detached leaves $(8-11 \mathrm{~cm}$ in diameter) of cucumber as described in the section "Stimulatory effects of spraying sublethal doses of carbendazim on the virulence of mycelia of B. cinerea." After the leaves sprayed with carbendazim dilutions were airdried for $1 \mathrm{~h}$, a volume of $5 \mu \mathrm{l}$ conidia suspension at approximately $1 \times 10^{6}$ conidia $\mathrm{ml}^{-1}$ was inoculated on the adaxial surface of each leaf. For each treatment, four leaves were inoculated as four replications. After being incubated at $23^{\circ} \mathrm{C}$ for $96 \mathrm{~h}$, the diameter of each lesion was measured twice at right angles. The experiment was conducted independently four times.

Stimulatory effects of carbendazim cosuspended with conidia on the virulence of $\boldsymbol{B}$. cinerea. Conidia were collected and counted as described above. Conidia suspensions $\left(1 \times 10^{6} / \mathrm{ml}\right)$ were added with appropriate volumes of carbendazim stock solution to make the ultimate concentrations of $0.0005,0.001,0.005,0.02$, and $0.1 \mu \mathrm{g} / \mathrm{ml}$ for isolate HB459; and $0.001,0.003,0.005,0.02,0.05$, and $0.1 \mu \mathrm{g} / \mathrm{ml}$ for isolate $\mathrm{HB} 536$. Conidia suspension added with $\mathrm{HCl}$ at a final concentration of $0.001 \mu \mathrm{g} / \mathrm{ml}$ was used as the nontreated control. After brief vortexing, an aliquot of $5 \mu \mathrm{l}$ conidial suspension was inoculated on the adaxial surface of each detached cucumber leaf. After incubating at $25^{\circ} \mathrm{C}$ for $96 \mathrm{~h}$, the diameter of each disease lesion was measured twice at right angles. The experiment was conducted in quadruplicate and performed independently four times.

Effects of sublethal doses of carbendazim on the expression levels of virulence-associated genes. The expression levels of five virulence-associated genes were determined as described by $\mathrm{Li}$ et al. (2017). Total RNA was extracted by the RNAiso Plus kit (TaKaRa Bio Inc.) from 3-day-old mycelia of isolate HB536 grown at $23^{\circ} \mathrm{C}$ on cellophane-overlaid PDA amended with carbendazim at 0.02 and $0.05 \mu \mathrm{g} / \mathrm{ml}$. Mycelia grown on PDA supplemented with $0.002 \mathrm{~mol} /$ liter $\mathrm{HCl}$ was used as the nontreated control. RNA purity was determined spectrophotometrically with a UV-1800 spectrophotometer (Shimadzu Co., Ltd., Japan). RNA was reverse-transcribed into cDNA
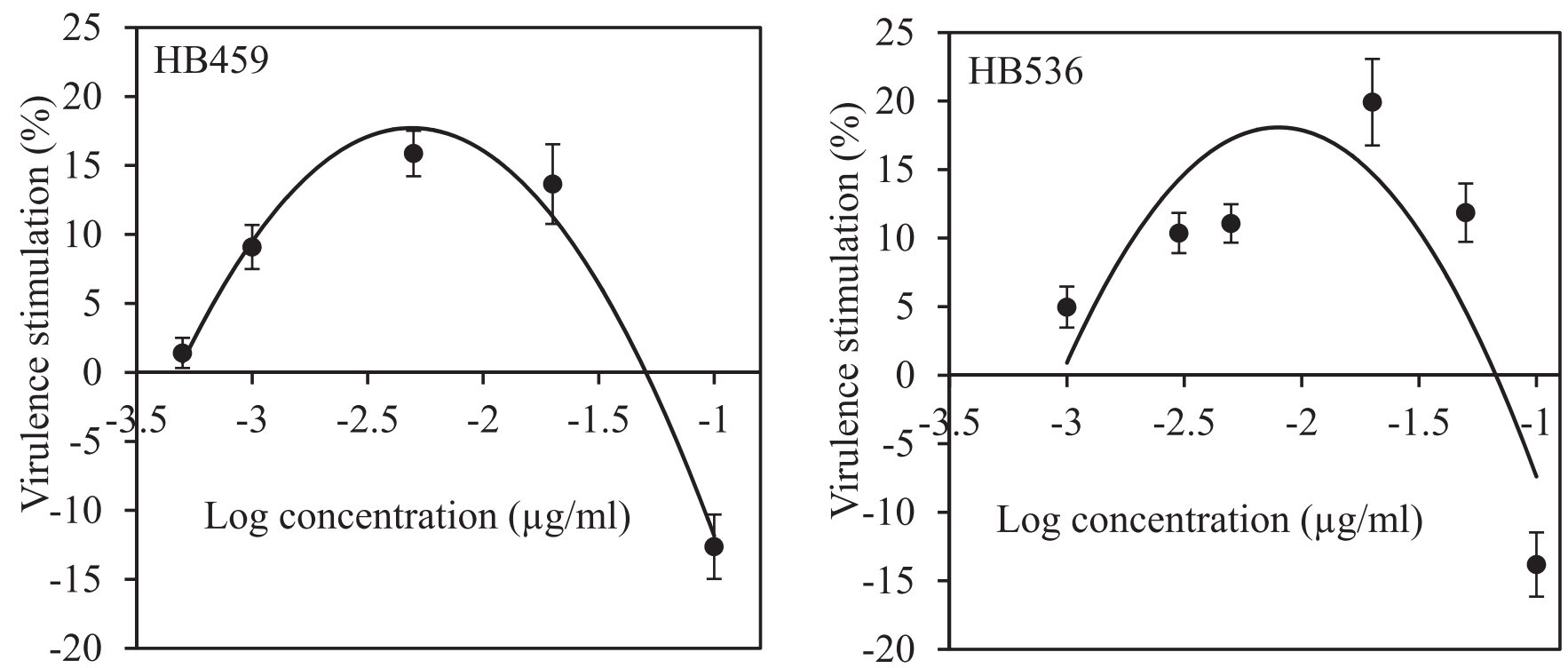

Fig. 5. Stimulatory effects of spraying sublethal doses of carbendazim on the virulence of conidia of Botrytis cinerea on detached leaves of cucumber plants. Data are the mean value of four repetitions, and error bars denote standard error of the mean. 
with the Hifair II first Strand cDNA Synthesis SuperMix kit (Shanghai Yeasen Biotech Co., Ltd., China) according to the manufacturer's manual. The $\beta$-tubulin gene was used as the reference gene. Unless stated otherwise, primers for quantitative PCR were designed online by NCBI Primer-BLAST (https://www.ncbi.nlm.nih.gov/tools/primerblast) based on DNA sequences of each gene retrieved from GenBank (https://www.ncbi.nlm.nih.gov/genbank/). The GenBank accession numbers were MG949129 for the $\beta$-tubulin gene of $B$. cinerea (Zhang et al. 2010), XM_024694543 for the pectin methylesterase gene Bcpme1 (Valette-Collet et al. 2003), Z69264 for the cutinase gene CutA (Van der Vlugt-Bergmans et al. 1997), and CAP12516 for the NADPH oxidase gene BcnoxA (Segmüller et al. 2008). Primer sequence for the endopolygalacturonase gene Bcpg2 was the same as described by Zhang et al. (2014) and for the xylanase gene Xyn11A as described by Brito et al. (2006). All primer sets were verified by melting curve analysis for the absence of nonspecific amplicons. Quantitative PCR was performed in a MyiQ2 Two-Color Real-Time PCR Detection System (Bio-Rad Laboratories Inc.). A total volume of $20 \mu l$ reaction mixture contained $1 \mu l$ of cDNA, $1 \mu l$ of each of the forward and reverse primers each at $10 \mu \mathrm{M}$ (Table 1), $10 \mu \mathrm{l}$ of $2 \times$ SsoFast EvaGreen Supermix (Bio-Rad, Hercules, CA, U.S.A.), and $7 \mu l$ of nuclease-free water. The thermal cycling conditions were $95^{\circ} \mathrm{C}$ initial denaturation for $30 \mathrm{~s}, 40$ cycles of denaturation at $95^{\circ} \mathrm{C}$ for $5 \mathrm{~s}$, primer annealing and elongation at $60^{\circ} \mathrm{C}$ for $10 \mathrm{~s}$. This cycle was followed by a melting curve analysis, with temperature increasing from 55 to $95^{\circ} \mathrm{C}$, in steps of $0.5^{\circ} \mathrm{C}$ every $10 \mathrm{~s}$. The transcription levels of each gene tested were normalized to the housekeeping gene $\beta$-tubulin. The relative levels of gene transcription were calculated with the $2^{-\Delta \Delta C T}$ method (Livak and Schmittgen 2001). Three biological replicates were used to calculate the mean and standard error of the mean.

Data processing and analysis. Percent virulence stimulations were calculated by the following formula: Percent stimulation $(\%)=$ [(Lesion diameter of the treated - Lesion diameter of the control)/ Lesion diameter of the control] $\times 100 \%$. Curve modeling for percent stimulations was performed as described by Deng et al. (2001) with the quadratic equation in the software SPSS (Statistical Product and Service Solutions, ver. 21.0; SPSS Inc.). Percent data were arcsine square-root transformed for a statistical significance test. The data for sclerotia production and transformed percentage data were analyzed by the general linear model (GLM) procedure in the software SPSS (ver. 21.0) with least significant difference (LSD) test as the Post Hoc multiple comparison method. Figures were constructed with the software Microsoft Excel (ver. 2013, Microsoft Corporation, Redmond, WA).

\section{Results}

Stimulatory effects of spraying sublethal doses of carbendazim on the virulence of $\boldsymbol{B}$. cinerea mycelia. Typical biphasic curves were obtained by quadratic regression analysis (Fig. 1). According to the quadratic curves, carbendazim at a dose range from 0.001 to $0.03 \mu \mathrm{g} / \mathrm{ml}$ had stimulatory effects on the virulence of both isolates. The maximum percent stimulations for isolates HB459 and HB536 were 15.5 and $21.4 \%$, respectively. The $R^{2}$ values of the quadratic curves for the two isolates were 0.98 and 0.68 , respectively. The $P$ values for the quadratic curves of the two isolates were 0.02 and 0.182 , respectively.

Stimulatory effects of preconditioned mycelia grown on carbendazim-amended PDA on the virulence of $B$. cinerea. Carbendazim in PDA at 0.001 increased mycelial growth of isolate HB 459 by $0.2 \%$, and carbendazim at 0.005 and $0.02 \mu \mathrm{g} / \mathrm{ml}$ inhibited mycelial growth of isolate HB459 by 3.3 and $13.6 \%$, respectively. However, after being inoculated on cucumber leaves, these

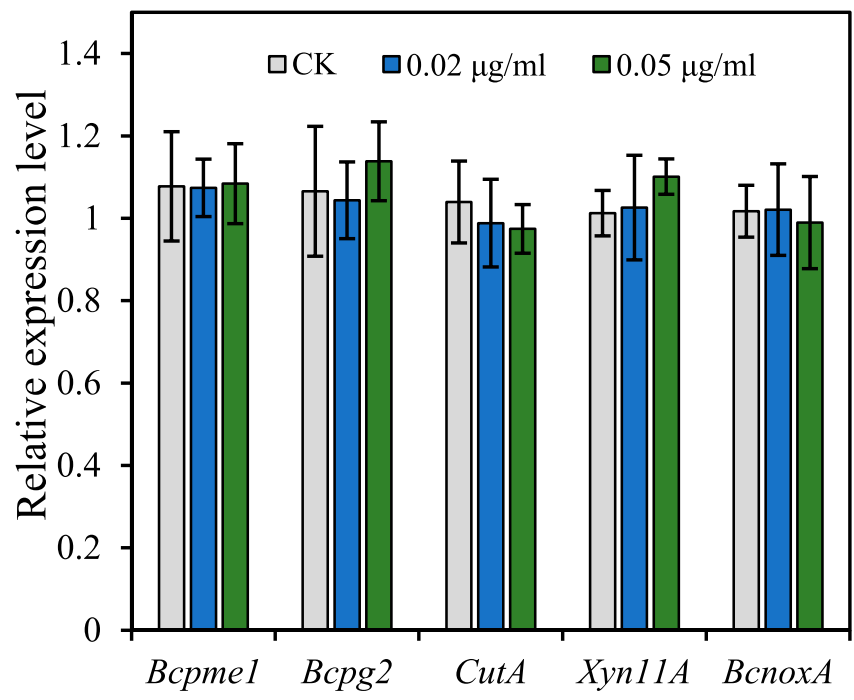

Fig. 7. Effects of sublethal doses of carbendazim on expression levels of virulenceassociated genes Bcpme1, Bcpg2, CutA, Xyn11A, and BcnoxA of Botrytis cinerea isolate HB536. Data are the mean value of three repetitions, and error bars denote standard error of the mean.
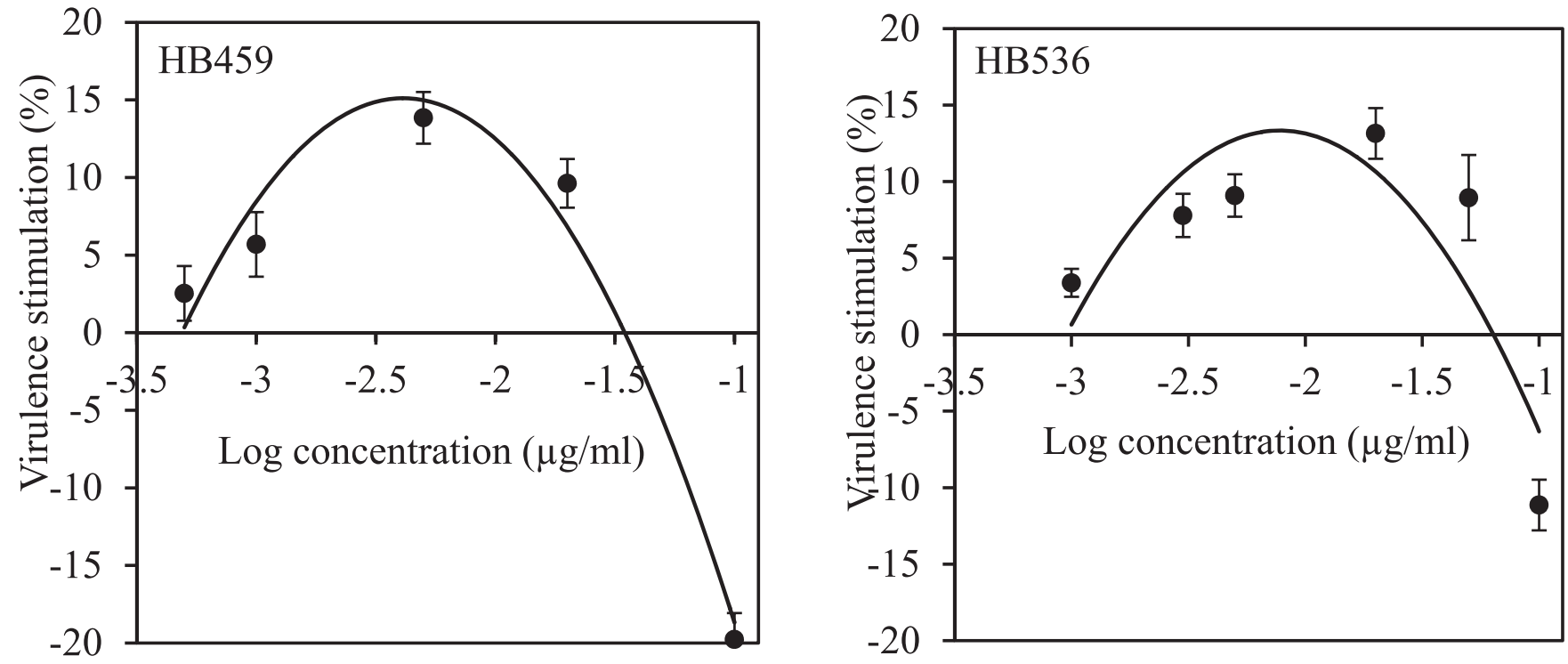

Fig. 6. Stimulatory effects of carbendazim cosuspended with conidia on the virulence of Botrytis cinerea isolates HB459 and HB536 on detached leaves of cucumber plants. Data are the mean value of four repetitions, and error bars denote standard error of the mean. 
preconditioned, i.e., slightly stimulated or inhibited mycelia exhibited percent virulence stimulations of $8.4,9.1$, and $6.7 \%$, respectively (Fig. 2). Similarly, carbendazim in PDA at 0.01, 0.02, and $0.05 \mu \mathrm{g} / \mathrm{ml}$ inhibited mycelial growth of isolate HB536 by 0.8 , 10.0 , and $30.6 \%$, respectively, and virulence increased by 10.1 , 12.9 , and $10.8 \%$, respectively. Carbendazim in PDA at relatively high concentrations of 0.08 and $0.1 \mu \mathrm{g} / \mathrm{ml}$ inhibited mycelial growth and virulence of both isolates.

Effects of sublethal doses of carbendazim on sclerotial production of $\boldsymbol{B}$. cinerea. Isolate HB459 produced more sclerotia than isolate HB536 (Fig. 3). For both isolates, the number of sclerotia produced on PDA amended with carbendazim at 0.005 and $0.02 \mu \mathrm{g} / \mathrm{ml}$ was statistically significantly $(0.021<P<0.046)$ higher than the nontreated controls. Similarly, the weight of sclerotia produced in the presence of 0.005 and $0.02 \mu \mathrm{g} / \mathrm{ml}$ carbendazim was significantly $(0.001<P<0.048)$ greater than that of nontreated control. Carbendazim in PDA at $0.1 \mu \mathrm{g} / \mathrm{ml}$ significantly $(P \leq 0.012)$ reduced the sclerotia number and weight of both isolates.

Effects of sublethal doses of carbendazim on conidial germination of B. cinerea. Carbendazim in PDA at 0.001 and $0.005 \mu \mathrm{g} / \mathrm{ml}$ increased conidial germination of isolate HB459 by $3.85 \%(P=$ $0.037)$ and $4.41 \%(P=0.018)$, respectively (Fig. 4), while carbendazim at $0.1 \mu \mathrm{g} / \mathrm{ml}$ inhibited conidial germination by $10.74 \%(P=$ 0.003). Similarly, carbendazim in PDA at 0.001 and $0.005 \mu \mathrm{g} / \mathrm{ml}$ increased conidial germination of isolate HB536 by $5.05 \%(P=0.020)$ and $6.43 \%(P=0.014)$, respectively, while carbendazim at $0.1 \mu \mathrm{g} / \mathrm{ml}$ inhibited conidial germination by $5.43 \%(P=0.029)$.

Effects of sublethal doses of carbendazim on the virulence of conidia of $\boldsymbol{B}$. cinerea. Carbendazim either sprayed on cucumber leaves (Fig. 5) or cosuspended with conidia (Fig. 6) had stimulatory effects on the virulence of conidia. For isolate HB459, the dose range of carbendazim with stimulatory effects on virulence was 0.0005 to $0.03 \mu \mathrm{g} / \mathrm{ml}$, and the maximum percent stimulation was $13.6 \%$ for spraying treatment and $13.4 \%$ for cosuspension treatment. For isolate HB536, the dose range of carbendazim with stimulatory effects was 0.001 to $0.05 \mu \mathrm{g} / \mathrm{ml}$, and the maximum percent stimulation was $19.9 \%$ for spraying treatment and $13.2 \%$ for cosuspension treatment.

Effects of sublethal doses of carbendazim on the expression levels of virulence-associated genes. Carbendazim in PDA at 0.02 and $0.05 \mu \mathrm{g} / \mathrm{ml}$ had statistically significant $(P<0.001)$ stimulatory effects on virulence of isolate HB536; however, carbendazim at 0.02 and $0.05 \mu \mathrm{g} / \mathrm{ml}$ did not show significant effects on the expression levels of any of the five virulence-associated genes including the pectin methylesterase gene Bcpme1, the endopolygalacturonase gene $B c p g 2$, the cutinase gene $C u t A$, the xylanase gene Xyn11A, and the NADPH oxidase gene BcnoxA (Fig. 7).

\section{Discussion}

The present study showed that carbendazim sprayed at concentrations of 0.001 to $0.03 \mu \mathrm{g} / \mathrm{ml}$ had stimulatory effects on the virulence of sensitive isolates of $B$. cinerea, and the maximum-stimulation dose for isolate HB536 was slightly higher than that for isolate HB459. Virulence stimulations for conidia and preconditioned mycelia also showed higher stimulatory doses for isolate HB536 than for isolate HB459. The relatively higher maximum-stimulation dose for isolate HB536 may be related to its higher $\mathrm{EC}_{50}$ value. A comparison with our previous studies on carbendazim-resistant $B$. cinerea demonstrated that the stimulatory carbendazim doses were approximately 1,000 -fold higher for resistant isolates than for the two sensitive isolates assayed in the present study (Cong et al. 2018). Studies on hormetic effects of thiophanate-methyl on $S$. homoeocarpa showed that there may be a positive correlation between $\mathrm{EC}_{50}$ values and the maximum-stimulation dose (Pradhan et al. 2019). These results indicate a positive correlation between fungicide sensitivity levels and the stimulatory doses of a fungicide, although we could not perform a correlation analysis at present due to limited isolates tested.

It is of note that the slightly and moderately inhibited mycelia exhibited considerable virulence stimulations on cucumber leaves without any fungicide. For example, carbendazim in PDA at $0.05 \mu \mathrm{g} / \mathrm{ml}$ inhibited mycelial growth of isolate HB536 by $30.6 \%$, and the inhibited mycelia exhibited virulence stimulation of $10.8 \%$. Carbendazim at the relatively high concentration of $0.1 \mu \mathrm{g} / \mathrm{ml}$ inhibited mycelial growth of the two isolates by more than $50 \%$, and subsequent inoculations on cucumber leaves showed inhibited virulence. Our previous studies also demonstrated that $S$. sclerotiorum mycelia slightly inhibited by flusilazole in PDA exhibit increased virulence to oilseed rape leaves ( $\mathrm{Lu}$ et al. 2018b). The present study showed carbendazim in PDA at $0.02 \mu \mathrm{g} / \mathrm{ml}$ inhibited mycelial growth of isolates HB459 and HB536 by 16.9 and $10.0 \%$, respectively, but significantly increased both sclerotial number and weight for the two isolates. These results have profound implications for understanding the concept of hormesis. Stimulations might be hidden in inhibitory phenotypes. Inhibitions for one parameter or endpoint might encompass stimulations if another parameter or endpoint is measured. Thus, hormesis may occur more commonly and frequently than we previously realized and recognized. Hormesis provides a quantitative estimate of biological plasticity, and the quantitative features of hormesis are highly generalizable, independent of biological model, endpoint measured, and chemical/physical stressinducing agent (Calabrese and Mattson 2011).

After the conidia produced on PDA without fungicide were plated on PDA amended with carbendazim at 0.001 and $0.005 \mu \mathrm{g} / \mathrm{ml}$, percent germinations increased slightly but statistically significantly compared with the nontreated controls. Subsequent investigations demonstrated that carbendazim either sprayed on cucumber leaves or cosuspended with conidia had significant stimulatory effects on the virulence of $B$. cinerea conidia. The quantitative features of the stimulation profiles such as the maximum stimulation magnitude and the stimulatory dose range were similar to those for mycelia stimulations. Our previous studies mainly focused on virulence stimulations for mycelia (Cong et al. 2018; Di et al. 2015, 2016a; Lu et al. 2018b; Zhou et al. 2014), and the present study showed that conidia also exhibited similar virulence stimulation profiles. These results indicate that fungicide hormesis is generalizable.

Elucidation of biochemical and molecular mechanisms for hormesis will deepen our understanding of this generalizable concept. Our previous studies showed that carbendazim at concentrations exerting virulence stimulations for carbendazim-resistant isolates of $\mathrm{B}$. cinerea (Cong et al. 2018) and S. sclerotiorum (Di et al. 2015) did not increase tolerance to hydrogen dioxide $\left(\mathrm{H}_{2} \mathrm{O}_{2}\right)$ or promote the production of oxalic acid, although stimulatory effects of dimethachlone and prochloraz on the virulence of $S$. sclerotiorum might be partially caused by increased tolerance to $\mathrm{H}_{2} \mathrm{O}_{2}$ (Zhang et al. 2019; Zhou et al. 2014). In order to explore the hormetic mechanisms of carbendazim on $B$. cinerea, effects of sublethal doses of carbendazim on the expression levels of several virulence-associated genes were studied in the present work. However, results showed that the expression levels of the pectin methylesterase gene Bcpme1, the endopolygalacturonase gene $B c p g 2$, the cutinase gene $C u t A$, the xylanase gene Xyn11A, or the NADPH oxidase gene BcnoxA were not affected by sublethal doses of carbendazim. There are plenty of various factors influencing the virulence of $B$. cinerea. Each virulence factor may play a unique role in different stages of the infection process (Nakajima and Akutsu 2014). The underlying molecular mechanisms for fungicide hormetic effects on $B$. cinerea remain to be investigated in the future.

\section{Literature Cited}

Audenaert, K., Callewaert, E., Höfte, M., Saeger, S. D., and Haesaert, G. 2010 Hydrogen peroxide induced by the fungicide prothioconazole triggers deoxynivalenol (DON) production by Fusarium graminearum. BMC Microbiol. 10:112.

Baraldi, E., Mari, M., Chierici, E., Pondrelli, M., Bertolini, P., and Pratella, G. C. 2003. Studies on thiabendazole resistance of Penicillium expansum of pears: Pathogenic fitness and genetic characterization. Plant Pathol. 52:362-370.

Brito, N., Espino, J. J., and Gonzalez, C. 2006. The endo- $\beta$-1,4-xylanase xyn 11 a is required for virulence in Botrytis cinerea. Mol. Plant-Microbe Interact. 19:25-32.

Calabrese, E. J. 2013. Hormetic mechanisms. Crit. Rev. Toxicol. 43:580-606.

Calabrese, E. J. 2015a. Hormesis: Principles and applications. Homeopathy 104: 69-82.

Calabrese, E. J. 2015b. Hormesis within a mechanistic context. Homeopathy 104: 90-96. 
Calabrese, E. J. 2016a. Preconditioning is hormesis part I: Documentation, doseresponse features and mechanistic foundations. Pharmacol. Res. 110:242-264.

Calabrese, E. J. 2016b. Preconditioning is hormesis part II: How the conditioning dose mediates protection: Dose optimization within temporal and mechanistic frameworks. Pharmacol. Res. 110:265-275.

Calabrese, E. J. 2018a. Post-conditioning hormesis creates a "subtraction to background" disease process: Biological, aging, and environmental risk assessment implications. J. Cell Commun. Signal. 12:31-34.

Calabrese, E. J. 2018b. Hormesis: Path and progression to significance. Int. J. Mol. Sci. 19:2871.

Calabrese, E. J., and Agathokleous, E. 2019. Building biological shields via hormesis. Trends Pharmacol. Sci. 40:8-10.

Calabrese, E. J., and Blain, R. B. 2011. The hormesis database: The occurrence of hormetic dose responses in the toxicological literature. Regul. Toxicol. Pharmacol. 61:73-81.

Calabrese, E. J., and Mattson, M. P. 2011. Hormesis provides a generalized quantitative estimate of biological plasticity. J. Cell Commun. Signal. 5:25-38.

Cong, M. L., He, S., Ma, H. J., Li, G. Q., and Zhu, F. X. 2018. Hormetic effects of carbendazim on the virulence of Botrytis cinerea. Plant Dis. 102:886-891.

Cong, M. L., He, S., Zhang, J., Luo, C. X., and Zhu, F. X. 2019. Hormetic effects of mixtures of carbendazim and iprodione on the virulence of Botrytis cinerea. Plant Dis. 103:95-101.

Deng, C., Graham, R., and Shukla, R. 2001. Detecting and estimating hormesis using a model-based approach. Hum. Ecol. Risk Assess. 7:849-866.

Di, Y. L., Cong, M. L., Zhang, R., and Zhu, F. X. 2016a. Hormetic effects of trifloxystrobin on aggressiveness of Sclerotinia sclerotiorum. Plant Dis. 100: 2113-2118.

Di, Y. L., Lu, X. M., Zhu, Z. Q., and Zhu, F. X. 2016b. Time-course of carbendazim stimulation on pathogenicity of Sclerotinia sclerotiorum indicates a direct stimulation mechanism. Plant Dis. 100:1454-1459.

Di, Y. L., Zhu, Z. Q., Lu, X. M., and Zhu, F. X. 2015. Pathogenicity stimulation of Sclerotinia sclerotiorum by subtoxic doses of carbendazim. Plant Dis. 99:1342-1346.

Fan, F., Hamada, M. S., Li, N., Li, G. Q., and Luo, C. X. 2017. Multiple fungicide resistance in Botrytis cinerea from greenhouse strawberries in Hubei province, China. Plant Dis. 101:601-606.

Flores, F. J., and Garzón, C. D. 2013. Detection and assessment of chemical hormesis on the radial growth in vitro of oomycetes and fungal plant pathogens. Dose Response 11:361-373.

Garzón, C. D., and Flores, F. J. 2013. Hormesis: Biphasic dose-responses to fungicides in plant pathogens and their potential threat to agriculture. Pages 311-328 in: Fungicides-showcases of integrated plant disease management from around the world. INTECH.

Garzón, C. D., Molineros, J. E., Yanez, J. M., Flores, F. J., Jimenez-Gasco, M. M., and Moorman, G. W. 2011. Sublethal doses of mefenoxam enhance Pythium damping-off of geranium. Plant Dis. 95:1233-1238.

Konstantinou, S., Veloukas, T., Leroch, M., Menexes, G., Hahn, M., and Karaoglanidis, G. 2015. Population structure, fungicide resistance profile, and $\mathrm{sdhB}$ mutation frequency of Botrytis cinerea from strawberry and greenhouse-grown tomato in Greece. Plant Dis. 99:240-248.

Li, J. L., Kang, T. H., Talab, K. M. A., Zhu, F. X., and Li, J. H. 2017. Molecular and biochemical characterization of dimethachlone resistant isolates of Sclerotinia sclerotiorum. Pestic. Biochem. Physiol. 138:15-21.

Livak, K. J., and Schmittgen, T. D. 2001. Analysis of relative gene expression data using real-time quantitative PCR and the $2^{-\Delta \Delta \mathrm{CT}}$ method. Methods 25:402-408.
Lu, X. M., He, S., Ma, H. J., Li, J. H., and Zhu, F. X. 2018a. Hormetic effects of flusilazole preconditioning on mycelial growth and virulence of Sclerotinia sclerotiorum. Plant Dis. 102:1165-1170.

Lu, X. M., Zhang, R., Cong, M. L., Li, J. H., and Zhu, F. X. 2018b. Stimulatory effects of flusilazole on virulence of Sclerotinia sclerotiorum. Plant Dis. 102: 197-201.

Mbengue, M., Navaud, O., Peyraud, R., Barascud, M., Badet, T., Vincent, R., Barbacci, A., and Raffaele, S. 2016. Emerging trends in molecular interactions between plants and the broad host range fungal pathogens Botrytis cinerea and Sclerotinia sclerotiorum. Front. Plant Sci. 7:422.

Nakajima, M., and Akutsu, K. 2014. Virulence factors of Botrytis cinerea. J. Gen. Plant Pathol. 80:15-23.

Pradhan, S., Miller, L., Marcillo, V., Koch, A. R., Grachet, N. G., Molineros, J. E., Walker, N. R., Melouk, H., and Garzón, C. D. 2019. Hormetic effects of thiophanate-methyl in multiple isolates of Sclerotinia homoeocarpa. Plant Dis. 103:89-94.

Rupp, S., Weber, R. W. S., Rieger, D., Detzel, P., and Hahn, M. 2017. Spread of Botrytis cinerea strains with multiple fungicide resistance in German horticulture. Front. Microbiol. 7:2075.

Saito, S., Michailides, T. J., and Xiao, C. L. 2016. Fungicide resistance profiling in Botrytis cinerea populations from blueberry in California and Washington and their impact on control of gray mold. Plant Dis. 100:2087-2093.

Segmüller, N., Kokkelink, L., Giesbert, S., Odinius, D., van Kan, J., and Tudzynski, P. 2008. NADPH oxidases are involved in differentiation and pathogenicity in Botrytis cinerea. Mol. Plant-Microbe Interact. 21: 808-819.

Valette-Collet, O., Cimerman, A., Reinault, P., Levis, C., and Boccara, M. 2003. Disruption of Botrytis cinerea pectin methylesterase gene Bcpmel reduces virulence on several host plants. Mol. Plant-Microbe Interact. 16:360-367.

Van der Vlugt-Bergmans, C. J. B., Wagemakers, C. A. M., and van Kan, J. A. L. 1997. Cloning and expression of the cutinase A gene of Botrytis cinerea. Mol. Plant-Microbe Interact. 10:21-29.

Van Kan, J. A., Stassen, J. H., Mosbach, A., Van Der Lee, T. A., Faino, L., Farmer, A. D., Papasotiriou, D. G., Zhou, S., Seidl, M. F., Cottam, E., Edel, D., Hahn, M., Schwartz, D. C., Dietrich, R. A., Widdison, S., and Scalliet, G. 2017. A gapless genome sequence of the fungus Botrytis cinerea. Mol. Plant Pathol. 18:75-89.

Williamson, B., Tudzynski, B., Tudzynski, P., and van Kan, J. A. 2007. Botrytis cinerea: The cause of grey mould disease. Mol. Plant Pathol. 8:561-580.

Zhang, C. Q., Liu, Y. H., and Zhu, G. N. 2010. Detection and characterization of benzimidazole resistance of Botrytis cinerea in greenhouse vegetables. Eur. J. Plant Pathol. 126:509-515.

Zhang, L. S., Hua, C. L., Stassen, J. H. M., Chatterjee, S., and Cornelissen, M. 2014. Genome-wide analysis of pectate-induced gene expression in Botrytis cinerea: Identification and functional analysis of putative D-galacturonate transporters. Fungal Genet. Biol. 72:182-191.

Zhang, R., Zhang, Y. C., Xu, Q. R., Li, J. H., and Zhu, F. X. 2019. Hormetic effects of mixtures of dimethachlone and prochloraz on Sclerotinia sclerotiorum. Plant Dis. 103:546-554.

Zhang, S., Panaccione, S. G., and Gallegly, M. E. 1997. Metalaxyl stimulation of growth of isolates of Phytophthora infestans. Mycologia 89:289-292.

Zhou, F., Liang, H. J., Di, Y. L., You, H., and Zhu, F. X. 2014. Stimulatory effects of sublethal doses of dimethachlon on Sclerotinia sclerotiorum. Plant Dis. 98 $1364-1370$ 